\title{
Specialization and Market Penetration of Bilateral Trade between Peru and United States: An Exploratory Analysis
}

\author{
Md Ekram Hossain ${ }^{1,4 *}$, Huang Dechun ${ }^{1}$, Changzheng Zhang ${ }^{1}$, Marco Antonio Nunez del Prado ${ }^{2}$, Vivien Kitty \\ Molnar ${ }^{1,3}$ \\ ${ }^{1}$ Business School, Hohai University, Nanjing-21100, China \\ ${ }^{2}$ School of Public Administration, Hohai University, Nanjing-21100, China \\ ${ }^{3}$ Business School, University of Debrecen, Debrecen, Hungary \\ ${ }^{4}$ Center for Research Innovation and Development (CRID), Dhaka-1207, Bangladesh \\ * E-mail of the corresponding author: mdekram hossain@hhu.edu.cn
}

\begin{abstract}
This paper aims to investigate the dynamics of bilateral trade, specialization and export market penetration of Peru's trade with the United States of America. This research explored Peru's potentials in export market penetration with the United States for 16 industry sectors. The paper also applied the Export Intensity, Import Intensity, Trade Intensity and Revealed Comparative Advantage (RCA) indices by analyzing data from 1992 to 2017 of 16 industry sectors (HS2 digits classification) of Peru's trade with the United States.

The investigation over the trading relationship between the two countries in the mentioned indexes revealed the status of specialization and market penetration of Peru for its 16-industry sector's trade with the United States. The results stated several measures and policy implications to be implemented for improving the specialization of the mentioned sectors of Peru's trade with the United States as well as it will contribute to the academic literature in this area.
\end{abstract}

Key Words: Sectorial Analysis, Export Specialization, Market Penetration, Peru, The United States

JEL Classification: F12, F13, F14, O24

DOI: $10.7176 / \mathrm{JESD} / 12-12-11$

Publication date:June $30^{\text {th }} 2021$

\section{Introduction}

Peru and the United States of America have a strong relationship, due to several agreements. The trading history between the United States of America and Peru started on 4 December 1991, under the government of President George HW Bush, throughout the States enacting the Andean Trade Preference Act (ATPA) Tariff Preferences Act that eliminated tariffs on a series of products from Peru, Colombia, Ecuador, and Bolivia. It aimed to strengthen legal craftsmen in these countries as alternatives to reducing and expressing drug production and trafficking in these countries.

The relationship between the USA and Peru became stronger when Peru joined NAFTA. This initiative tends to seek for imports and exports increment, as eliminating tariffs, benefiting market's accessibility, regulating trade activity, and setting fixed regulations in trade agreements. Furthermore, it eliminates tariffs on imports and exports between the three countries. Tariffs are taxes used to make foreign goods more expensive. It has created specific rules to regulate trade in farm products, automobiles, and clothing. These also apply to some services, such as telecommunications and finance. Also, it provides an agreement between the members of the agreement to allow business travelers easy access to each other's countries.

Peru and the USA are members of the Asia-Pacific Economic Cooperation, which is the leading forum in the AsiaPacific to facilitate trade and investment, economic growth, and regional cooperation. This agreement helps members to cooperate more efficiently.

Peru is the first country in Latin America to be accepted into the WTO Standards Alliance program launched by the United States in November 2012. Peru will benefit from the program by having access to specialized training regarding the WTO TBT Agreement; by receiving orientation for Peruvian officials regarding standardization, regulatory and metrology systems; and by obtaining specialized assistance in evaluating Peruvian regulatory agencies' compliance with the TBT Agreement.

Because of the Bilateral Trade Agreement, the trade between Peru and the USA has been improving. Since 2009, total trade between the United States and Peru has risen from close to $\$ 9$ billion to $\$ 15.9$ billion in 2017. On the other hand, we can find some negative effects on the Peruvian market, because several domestic markets were replaced by foreign stores operated mostly by American brands or American managers. As the entry to invest in the country became easier for Americans under the treaty's benefits, several investors flew to the country to established foreign stores which increased the country's capital but at the same time, it created a competition to 
the local market.

Figure 1 and Figure 2 show the main export and import partners of Peru. We can see that China and the United States of America are playing a key role in the Peruvian economy.

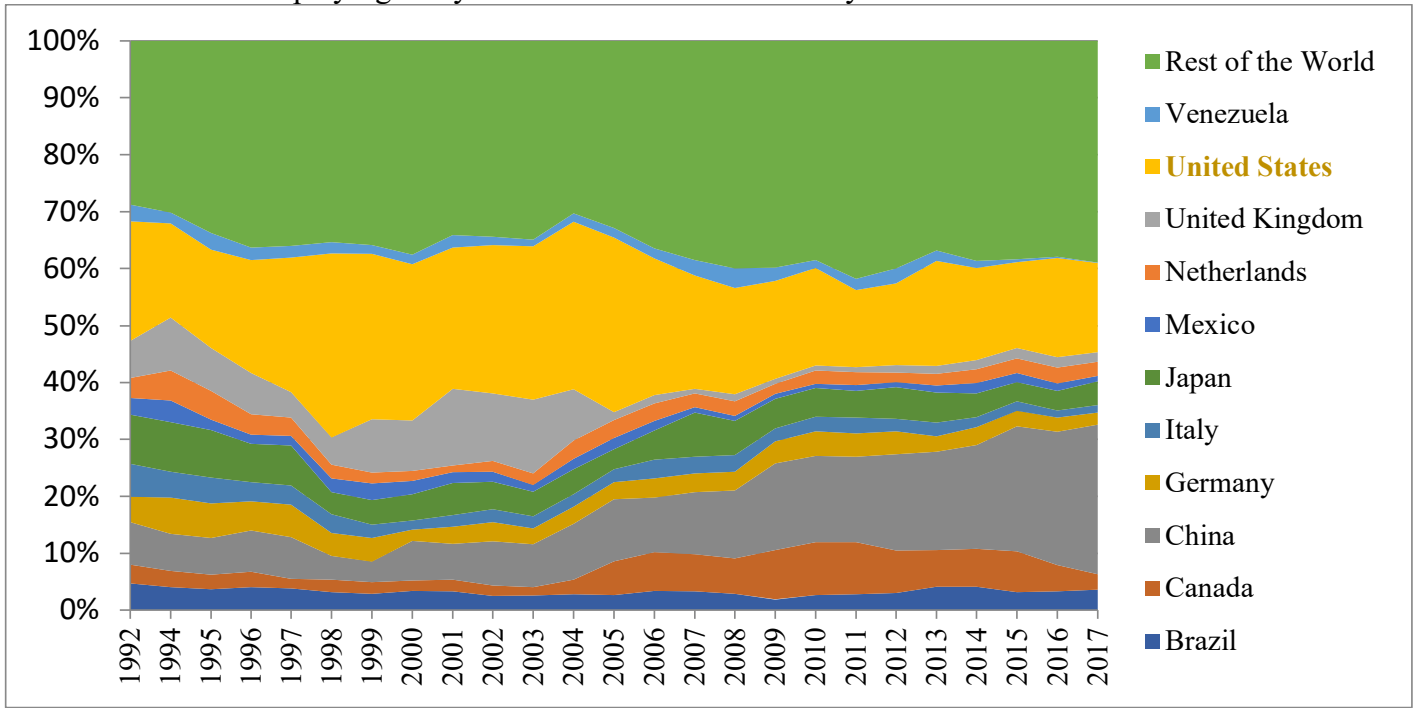

Figure 1: Export Partners of Peru between 1992 and 2017

Peruvian major export products to the States are mining products, seafood, textiles, coffee, fuels, "maca and quiche" and agricultural products, while the main import products from the USA are agricultural products, fuels, machines and electronic products.

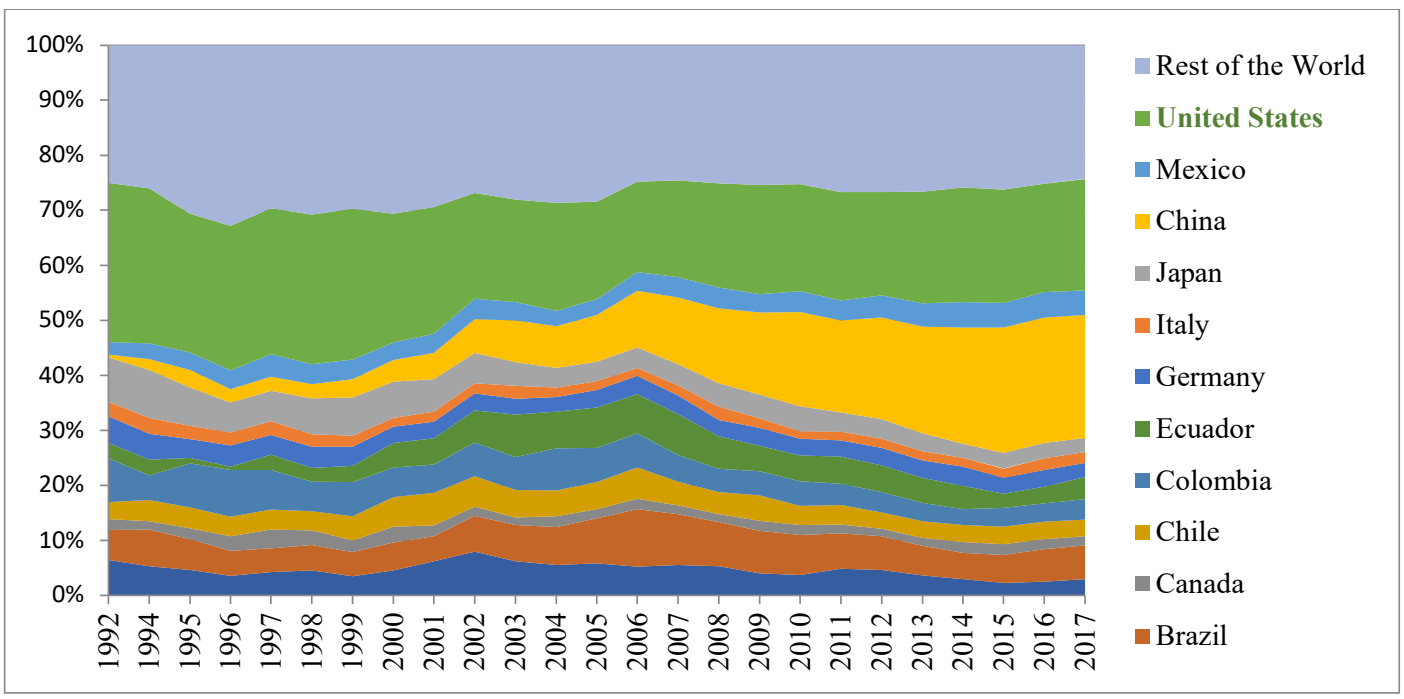

Figure 2: Import Partners of Peru between 1992 and 2017

Because of the importance of American relationship, this study has been carried out the following specific objectives:

i. What is the propensity of trade between Peru and the United States in general and at the sectoral level?

ii. Which sectors have the potentiality to contribute to minimizing the trade deficit of Peru to the United States?

iii. In which specific product groups in subsector level of Peru should emphasize more to get the larger export share to the United States.

\section{Literature Review}

A bilateral trade agreement confers favored trading status between two nations. By giving them access to each other's markets, it increases trade and economic growth. The terms of the agreement standardize business operations and level the playing field. When we talk about bilateral trade, we refer to cross-border transactions 
that occur between two countries. This is a binding agreement aimed at eliminating trade barriers, consolidating access to goods and services, and stimulating private investment in and between both countries. In addition to trade issues, it covers, inter alia, economic, institutional, intellectual property, labor, and environmental policies.

Bilateral trade relations and their intensity have appeared as one of the fundamental topics in international economics. The gravity model (in basic or modified form) has become an important analytical tool for examining a wide range of determinants of bilateral trade processes. Therefore, trade intensity indexes allowed assessing whether the value of trade between two countries is greater or smaller than would be expected based on their importance in world trade. Besides, Frankel (1997) introduced a trade intensity indicator for 'regional trading blocks' to assess whether the region exports more (in percentage) to a given destination than the world average. Empirical evidence based on various trade gravity models and various trade intensity indices belongs to a wide variety of bilateral trade relations studies (Folfas 2011).

The intensity of trade index was pioneered by Brown (Agnew and Crobridge 2002) and was later developed and popularized by Kojima (Kojima 1964). Kojima's intensity of trade index concentrates on variations in bilateral trade levels that result from differential resistances (Bano 2014). Trade with a country can be more intense than with the rest of the world, as resistance is lower. Trade Intensity help to measure these trade relationships without distortion due to the comparative size of trading partners (Bano 2014). When examining the strength of trade relations, it is often desirable to consider the importance of the country's trading partners in world trade. (Bhattacharyay and Mukhopadhyay 2015) (Chase-Dunn, Kawano, \& Brewer, 2000). One group of indices that do this is the trade intensity index (TII) (WITS 2019). The intensity of bilateral trade between two countries can be measured from either an export or import perspective. The trade intensity statistic is the ratio of two export shares (Raj, Wing, et al. 2014). The numerator is the share of the destination of interest in the exports of the region under study. The denominator is the share of the destination of interest in the exports of the world as a whole (ARTNET 2013).

\section{Data, Model and Methodology}

We explored the issues by constructing various trade indices using export and import data disaggregated at the Product group classification based on 2 digit Harmonized System (HS) 1988/92 for the period 2010-2016 based on secondary data sources of United Nations Commodity Trade database UN COMTRADE (Database, 2016), World Trade Organization (WTO, 2016), World Integrated Trade Solution (WITS), International Trade Center (ITC), Atlas of MIT Media Lab. To analyze the indices Microsoft Excel and SPSS software were used. To find out the objectives, at the first step we analyzed the export intensity of Peru to the United States, import intensity of the United States from Peru, and trade intensity of Peru to the United States. Then the revealed comparative advantage indexed has been analyzed to find out the specialization of 97 product groups of 16 sectors (all export sectors) of Peru export to the United States.

\subsection{Trade Intensity}

The intensity of trade index was pioneered by Brown (Brown, 1974) and was later developed and popularized by Kojima (Kojima, 1964). Kojima's intensity of trade index concentrates on variations in bilateral trade levels that result from differential resistances Bano (Bano, 2014). Trade may be more intense with a country and its trading partners than with the rest of the world because the resistance between them is lower. Trade intensity provides a way of measuring these trading relations without the bias resulting from the comparative size of the trading partners (Bano, 2014). In studying the strength of trade ties, it is often desirable to take into account the importance of a country's trade partners' share in world trade (Bhattacharyay \& Mukhopadhyay, 2015). One group of indices that does this is the trade intensity index (TII) (WITS, 2013).

The intensity of bilateral trade between two countries can be measured from either an export or import perspective. The trade intensity statistic is the ratio of two export shares (Raj, Wing, \& Ambrose, 2014). The numerator is the share of the destination of interest in the exports of the region under study. The denominator is the share of the destination of interest in the exports of the world as a whole (UNSCAP, 2016).

His paper attempts to analyze the USFDA import refusal report and the export competitiveness of Indonesian crab in the US market (Fahmi, Maksum, \& Suwondo, 2015).

To examine whether the bilateral trading relationship between Peru and the United States is strengthening or weakening, both export-intensity index and import-intensity index have been estimated. Here, Peru is reported as the home country $i$ and trading partner (USA) as country $j$. For trade flows from country i to country $j$, these indices are measured as follows: 
i. Export Intensity Index

$$
X I I_{i}=\frac{X_{i j} / X_{i w}}{M_{j w} /\left(M_{w t}-M_{i w}\right)}
$$

ii. Import Intensity Index

$$
M I_{i}=\frac{M_{i j} / M_{i w}}{X_{j w} /(X w t-X i w)}
$$

iii. Trade Intensity Index

$$
T I I_{i}=\frac{X_{i j} / X_{i t}}{X_{j w} / X_{w t}}
$$

Where: XII represents the export intensity index for country i; MII represents the import intensity index for country $\mathrm{i}$; and TII represents the Trade intensity index for country $\mathrm{i}$.

Xij represents the value of country i's exports to country j; Xiw represents the value of country i's total exports to the world; Mjw represents the total value of imports from the world into country $\mathrm{j}$; Mwt represents the value of total world imports; Miw represents the total value of imports from the world into country $\mathrm{i}$; Mij represents the value of country i's imports from country $\mathrm{j}$; Miw represents the total value of imports from the world into country i; Xw represents the total value of world exports; Xiw represents the value of country i's total exports to the world; Xit represents the value of country i's total exports to the world; Xwt represents the total value of world exports. The index determines whether bilateral trade between countries $\mathrm{i}$ and $\mathrm{j}$ is greater or lesser than might be expected given the importance of the trading partner's share in total world trade. As discussed by Bano (2008) (Bano \& Tabbada, 2012), trade intensity indices provide a way to measure the strength of $v$ trading relations without the bias caused by the comparative size of the trading partners. A value greater than one indicates that the relationship between the home country and the trading partner is greater than is expected given the trading partner's share of world trade, while a value of less than one indicates that the strength of the trading relationship is less than is expected (Bano \& Tabbada, 2012).

Limitations: As with trade shares, high or low-intensity indices and changes over time may reflect numerous factors other than trade policy (WITS, 2013).

\subsection{Revealed Comparative Advantage}

Revealed comparative advantage indices (RCA) use the trade pattern to identify the sectors in which an economy has a comparative advantage, by comparing the country of interests' trade profile with the world average. In other words, it is the ratio of the exports of the commodity from the source to total exports from the source, over the same ratio for the world (Fertő \& Hubbard, 2002). In this paper, we used Balassa's (Balassa, 1965) RCA model to measure the relative export performance by country and industry/commodity, defined as a country's share of world exports of a commodity divided by its share of total world exports (Balassa, 1977, 1979; Bela, 1986; Seyoum, 2007). The index for country $\mathrm{i}$ commodity $\mathrm{j}$ is calculated as follows:

$$
R C A_{i j}=\frac{X_{i j} / X_{w j}}{X_{t} / W_{t}}
$$

Where $R C A_{i j}$ is revealed comparative advantage of country i for Product $\mathrm{j}$, The value of $\mathrm{i}$ implies from 1 to $\mathrm{n}$ numbers, likely $\mathrm{j}$ implies from 1 to m numbers.

$X_{i j}$ denotes export by country i of Product j; $X_{w j}$ denotes total amount of global exports of Product j; $X_{t}$ denotes total global exports of country i; $X_{w}$ denotes total amount of global exports.

The index of revealed comparative advantage $R C A_{i j}$ has a relatively simple interpretation. It Takes values between $-\infty$ and $+\infty$. The value may be equal, greater or less than 1 . 


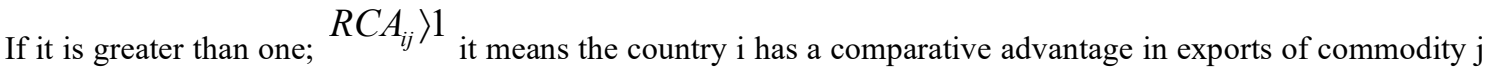
because its market share is larger in the commodity than its share in total exports and vice versa. If the value $R C A_{i j}\langle 1$ it interprets the vice versa.

The advantage of using the comparative advantage index is that it considers the intrinsic advantage of a particular export commodity and is consistent with changes in an economy's relative factor endowment and productivity. The disadvantage is that it cannot distinguish improvements in factor endowments and pursuit of appropriate trade policies by a country (De Benedictis \& Tamberi, 2001) (Sanidas \& Shin, 2010), (Hanson, Lind, \& Muendler, 2015) (FAO, 2015).

\subsection{Export Market Penetration}

Export Market Penetration indicator measures the extent to which a country's exports reach already proven markets. It is calculated as the number of countries to which the reporter exports a particular product divided by the number of countries that report importing the product that year. A low export penetration may signal the presence of barriers to trade that are preventing firms from expanding the number of markets to which they export. The index explained as follows;

$$
E M P=X_{i j k} / M_{j k}
$$

Xijk is defined as the share of country i's exports of good k to country j and Mjk is defined as country j's total imports of good k during the period.

However, the EMP is subject to the influence of the relative economic size of countries.

The index used in the paper slightly differs from the original one since the weights proposed by Lafay (1992) are the shares of trade in each sector relative to GDP. The relevance of the intra-industry trade phenomenon in Accession countries explored by Fidrmuc et al. (1999). Even if in the paper we will refer to a negative value of the Lafay index as "de-specialization" or "comparative disadvantage", this does not mean that the trade-in of those sectors is not advantageous in terms of welfare for the economy.

\section{Results and Discussion}

Export and Import Intensity

Figure 3 shows the results of the export and import intensity of Peru with the United States. In 2001 Peru had to face a political crisis, then in 2008, the global financial crisis had a bad effect on the Peruvian economy as well. Because of these issues, the composition of trade and export has been changed. During the analyzed 22 years, we can see that value of the export intensity index of footwear, food, chemical, plastic and rubber, and mineral products is lower than one, which means that the relationship between Peru and the United States is lower than expected given the importance of the USA's share in global trade.

This means that Peru should concentrate more on the textile and clothing industry, the agricultural sectors, footwear, and transportation sectors because the relationship between Peru and the USA in these sectors is stronger than in the others.

The value of animals, vegetables, machines and electronic products, stone and glass products, fuels, textile and clothes products are higher than one, which means that the export level from Peru to the USA is higher than that of Peru's in the world market share. Because of the crisis, the indexes have been changed due to political and economic effects, however, the main changes happened in the transportation, wood, hides and skins, metal, and agricultural sectors. The mentioned crisis affected the most on these sectors. The value of the fuel sector is halved, while the value of the metal sector before the 2001 crisis was increasing rapidly, then in 2017 almost dropped to 1992 value. The index of transportation sector was very changeable as well, however in last years, it seems headed in a positive direction and the values are getting more intensive year by year. Another major change occurred in the wood sector because the value of this sector was more than 3 , which means that the trade relationship was very intensive, but at the end of 2017 , this value is close to zero, which means that this sector is not negotiable as much as it was before. The value of agricultural sectors is higher than one, but because of the economic issues, these sectors' crises had a big negative impact on them. 

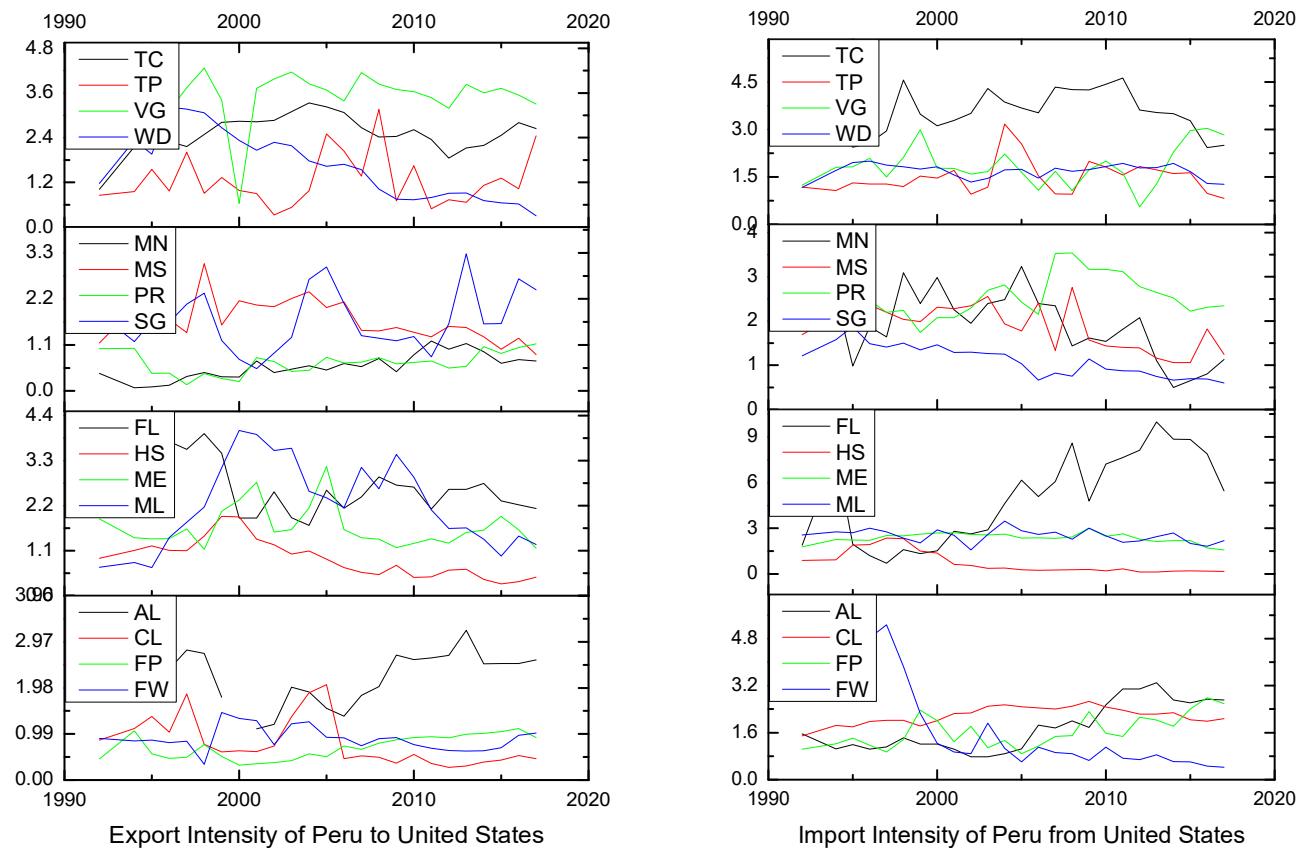

Figure 3: The Analyzed Result of Export and Import Intensity of Peru with the United States ${ }^{1}$

Most of the sectors, like textile and clothes, plastic and rubber, machine and electronic, metal and wood have a high value of import intensity, higher than one. It means interprets that the import level from the USA to Peru is higher than that of Peruvian share of the import from the world.

There are three sectors, stone and glass, hides and skins and transportation, where the value is lower than one, which means that the trade relationship is not that intensive. However, we can see that in 2004 the value of the transportation sector reached 3, but then the value began to decline rapidly and by 2017 it was close to zero. The biggest changes were in the fuel, animal, mineral, miscellaneous and footwear industry. The value of the fuel and animal sector has grown steadily, and the fuel sector has the highest value among sectors by the end of 2015. The biggest drop is seen in the footwear sector, by the end of 2017 , the value is close to zero.

\footnotetext{
${ }^{1}$ AL-Animal; CL-Chemicals; FP-Food Products; FW-Footwear; FL-Fuels; HS-Hides and Skins; ME-Mach and Elec.; MLMetals; MN-Minerals; MS-Miscellaneous; PR-Plastic or Rubber; SG-Stone and Glass; TC-Textiles and Clothing; TPTransportation; VG-Vegetable; WD-Wood
} 


\section{Trade Intensity}
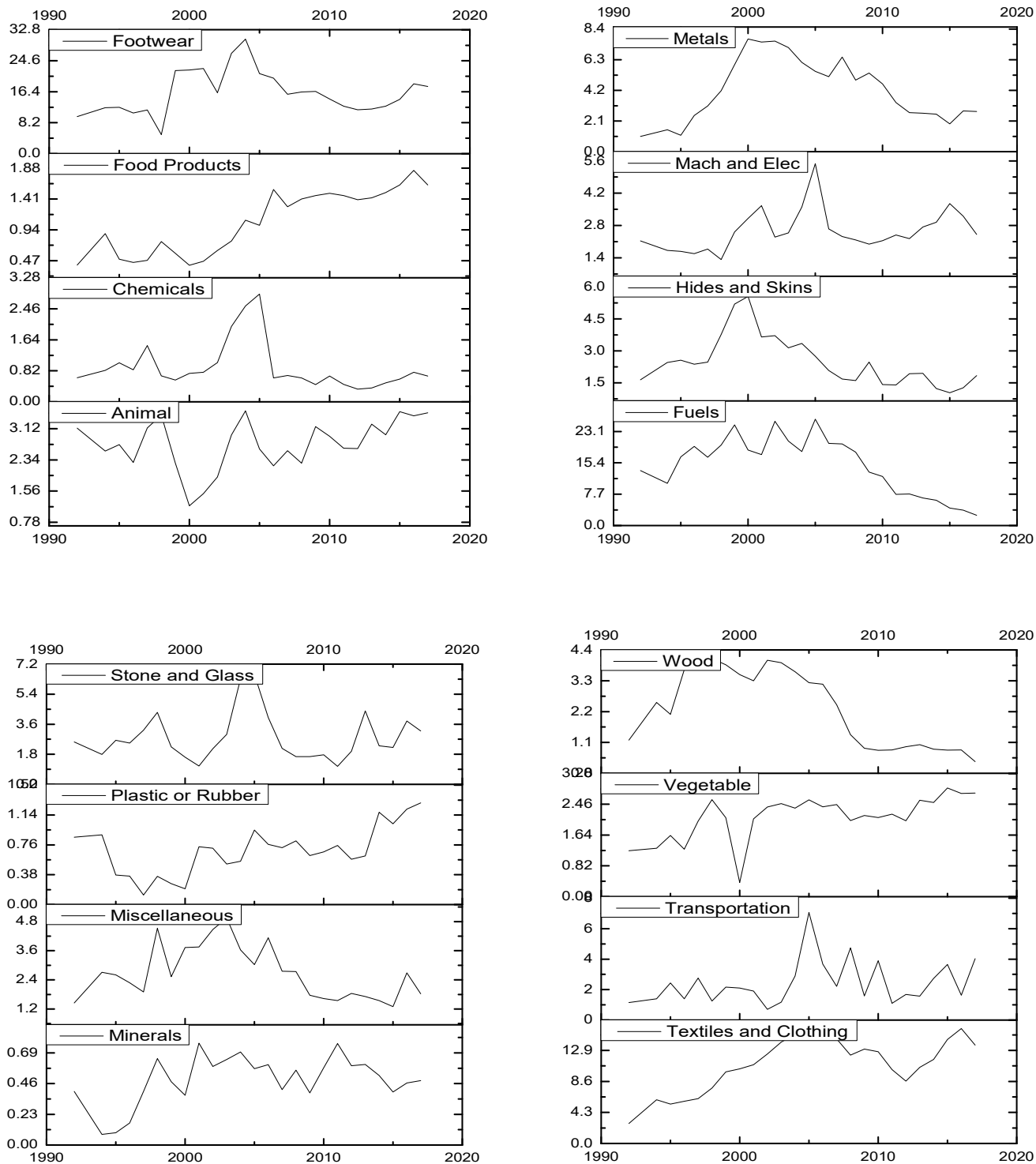

Figure 4: The Analyzed Result of Trade Intensity of Peru with the United States during 1992-2017

Figure 4 shows the trade intensity of Peru with the United State of America. The biggest changes happened in the fuel, textile and clothing sectors. The fuel sector has had the highest value from 1992 still the early 2000's, but then it started to drop rapidly and at the end of 2017 the result is close to zero, which means that the strength of the trading relationship is less than is expected. The opposite phenomenon happened in the textile and clothing sectors. The values of this sector increased intensively.

In the wood, chemical, metals, hides and skins sectors, we can see that their graphs are conical. Their values are increasing but then after the early 2000s, their values are decreasing. The most visible and drastic changes happened in the wood sector, in 2017 its value is close to zero.

The plastic and rubber and mineral sectors values are close to zero, which means that the trade relationship is intense.Highly intensive sectors are footwear, transportation, stone and glass, miscellaneous sector, the relationship is stronger than is expected. The agricultural sectors are intensive as well. During the fifteen years, food products have become an intensive sector as well. Furthermore, the values of the animal and vegetable sectors are higher 
than one, which means that the relationship is bigger than it is expected.

Revealed Comparative Advantage

Figure 5 shows the Revealed Comparative Advantage between Peru and the USA. Peru has a high comparative advantage (the values are higher than five) in the vegetable, animal, stone and glass and mineral sectors and medium comparative advantage (values are between one and five) in the footwear, fuel sector and food products, which means that Peru should focus more on them. The metal sector's graph is conical, at the beginning of the 2000's Peru had a high comparative advantage in this sector, but then the value started to decrease. However, Peru still has a medium comparative advantage in the metal sector.
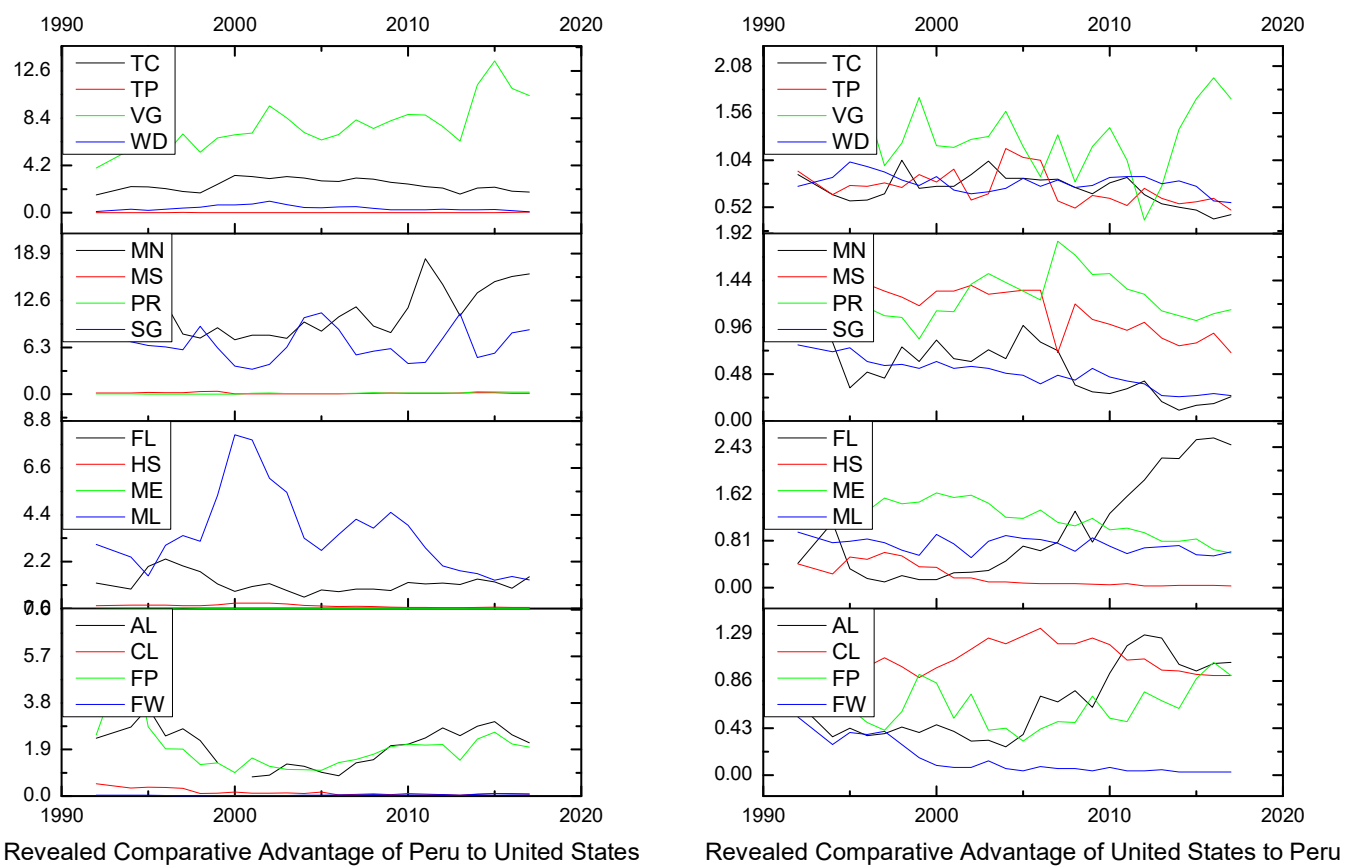

[Note: AL-Animal; CL-Chemicals; FP-Food Products; FW-Footwear; FL-Fuels; HS-Hides and Skins; ME-Mach and Elec.; ML-Metals; MN-Minerals; MS-Miscellaneous; PR-Plastic or Rubber; SG-Stone and Glass; TCTextiles and Clothing; TP-Transportation; VG-Vegetable; WD-Wood]

Figure 5: The Analyzed Result of Revealed Comparative Advantage (RCA) Between Peru and United States during 1992-2017

The results of RCA show that the values of the American sectors not as high as the Peruvians, because none of them could be higher than 2.43. America has a medium advantage in chemicals, miscellaneous, vegetables, plastic and rubber, machines, and electronic products. However, the values of the machines and electronics and miscellaneous are decreasing constantly.

The results in the animal, fuel and food products sectors are increasing as well, the States has the as medium comparative advantage of them. The other sectors' values are between one and zero, but none of them are negative, which means that the USA does not have a comparative disadvantage.

\section{Export Market Penetration}

The export market penetration (Figure 6) that medium level of market penetration exhibits in the animal sector of Peru with the United but for chemical products, it didn't reveal that level of penetration. For food products, the export market penetration shows a bit ups and downs but from 2013 to 201717 the penetration showed an upright. The food sector doesn't show that much penetration regarding trade with the United States. However, the hides and skins, Electrical Products, Food, miscellaneous, transportation sector, transportation sector revealed very low market penetration of Peru it's trade with the United States.

The metals sector showed a quite good Market penetration until 2010 but after 2013 the market penetration got down consequently. The mineral sector revealed one of the highest Market penetration sectors for Peru with its 
trade with the United States and it shows a really promising and potential sector for Peru for its market penetration with the United States. The stone and glass sector also showed a quite satisfactory Market penetration. The agricultural sector spatially the vegetable sector showed a quite high Market penetration and very promising sector for Peru's trade with the United States.
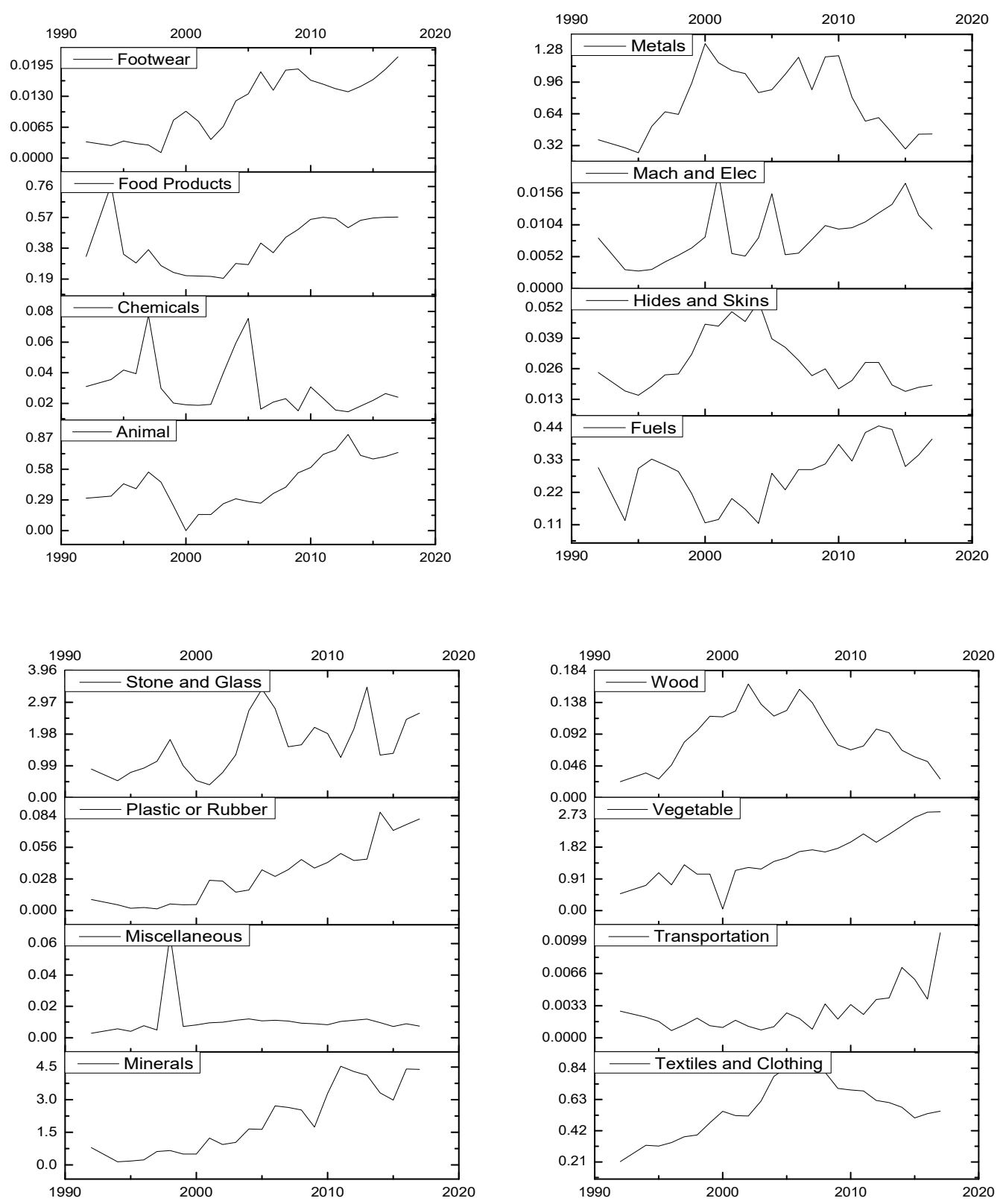

Figure 6: The Analyzed Result of Export Market Penetration of Peru to the United States during 1992-2017 The concluding remarks can we made in this regard that some few sectors among the 16th and Allied sectors between Peru and the United States for peruse Market penetration revealed that the mineral sector, Stone and glass sector, textile and clothing sector, and in some extent vegetable sector and Metal sector are the promising sectors that exhibited a quite satisfactory level of Market penetration for Peru for its trade with the United States. Accordingly, it is suggested Peru should focus on these sectors for its further trade development with the United States that could provide more advantages for peruse for its trade with the United States. 


\section{Conclusion}

This paper explores the trade between Peru and the United States of America, including trade intensiveness. We were looking for the answers to how the intensity of demand between the two regions has evolved, furthermore which sectors have the potentiality to contribute to minimizing the trade deficit of Peru to the United States and Peru should emphasize more to get the larger export share.

The results show that the agricultural, textile, and clothing products and raw materials like metal and plastic, and rubber have high export intensity indexes, meanwhile, the import intensity indexes of the fuel sector, chemicals, and raw materials are high. The trade is intensive between Peru and U.S., especially in footwear, the agricultural sector (animal, vegetable), stone and glass sector, transportation, and miscellaneous. The wood industry was an important sector as well, but it has lost its strength and over time other sectors started to play an important role. The same phenomenal happened in the fuel sector because it was an important part of the trade Peruvian-American trade, but because of the economic and political changes, the trade intensity decreased drastically.

The agricultural sector (vegetable, animal and food products), footwear, textile and clothing sectors have the potentiality to contribute to minimizing the trade deficit Peru has a high and medium comparative advantage in the three-three sector; vegetable, stone and glass, fuel, animal, textile and clothing, food products, minerals, and footwear; which means that the Peruvian government should focus more on these sectors. Especially, Peru should concentrate more on the mineral sector, because it has a high comparative advantage, however, the export and trade intensity of this sector is very low. Improving and developing the technology in this sector can cause a great output and Peru can get a larger export share. Furthermore, the government should put more effort into the food and footwear sector, because the country has a high comparative advantage in these sectors, meanwhile, the export intensiveness is low. The biggest changes have happened in the textile and clothing sector. During these 15 years, the intensiveness of this sector has been increasing rapidly and this area has a medium comparative advantage as well, which means that this sector can help to minimize the trade deficit and get a higher export share.

\section{Funding Information}

Financial support from the Innovative Team Project of Philosophy and Social Sciences in Jiangsu Higher Learning Institutions, Lancang-Mekong Cooperation Innovation and Risk Management under the "Belt and Road Initiative" (Grant Serial Number: 2017ZSTD002) of Hohai is gratefully acknowledged.

\section{Acknowledgments}

The authors thank the anonymous researchers at the Institute of Industrial Economics of Hohai University for their valuable comments for improving this paper.

Conflict of Interests Statement

There are no conflicts of interest declared by the authors. 


\section{Appendix:}

Appendix 1: Export, Import and Trade Balance of Peru in Global and with the United States
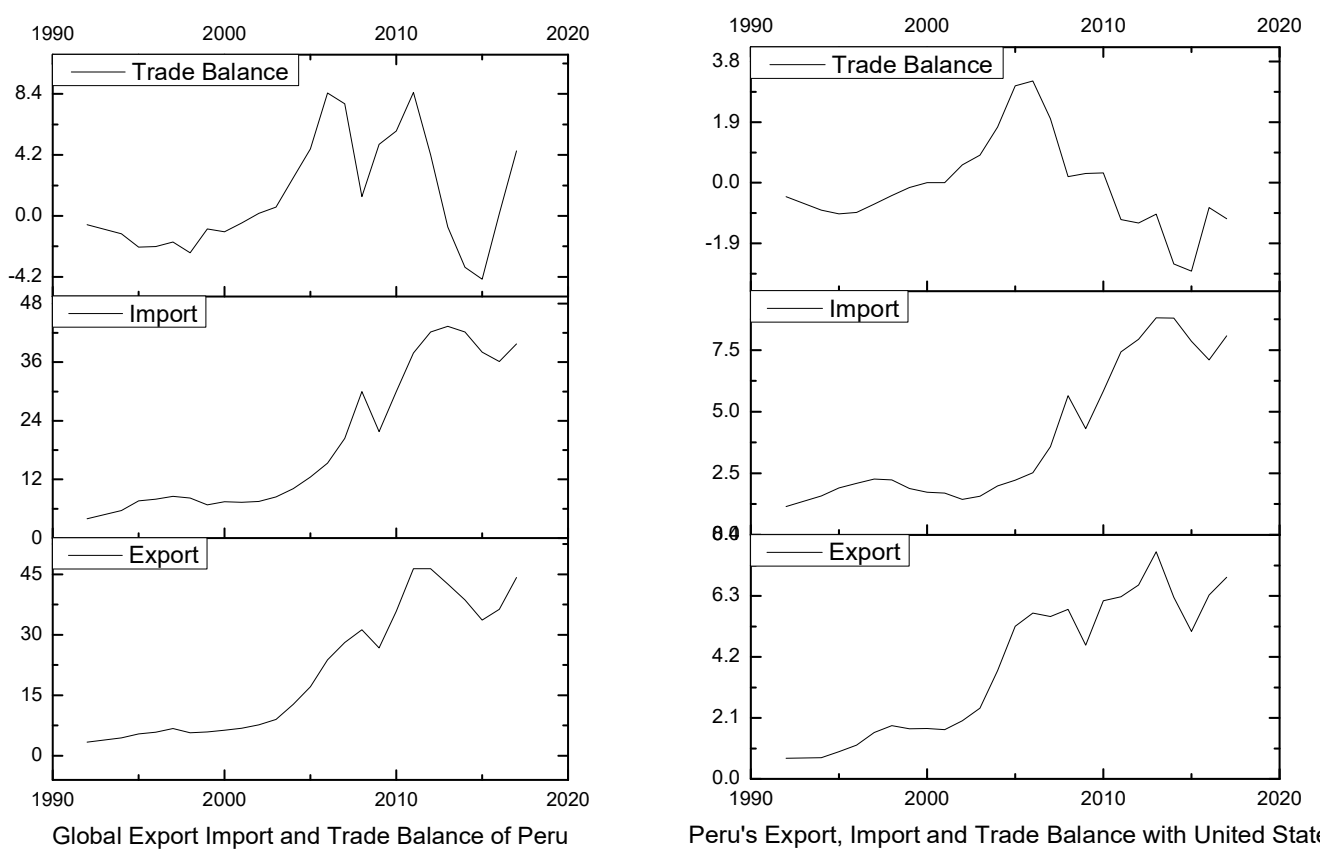

Peru's Export, Import and Trade Balance with United States

\section{Appendix 4: Share of Peru's Export to the United States by Larger Sector (16 Sectors)}

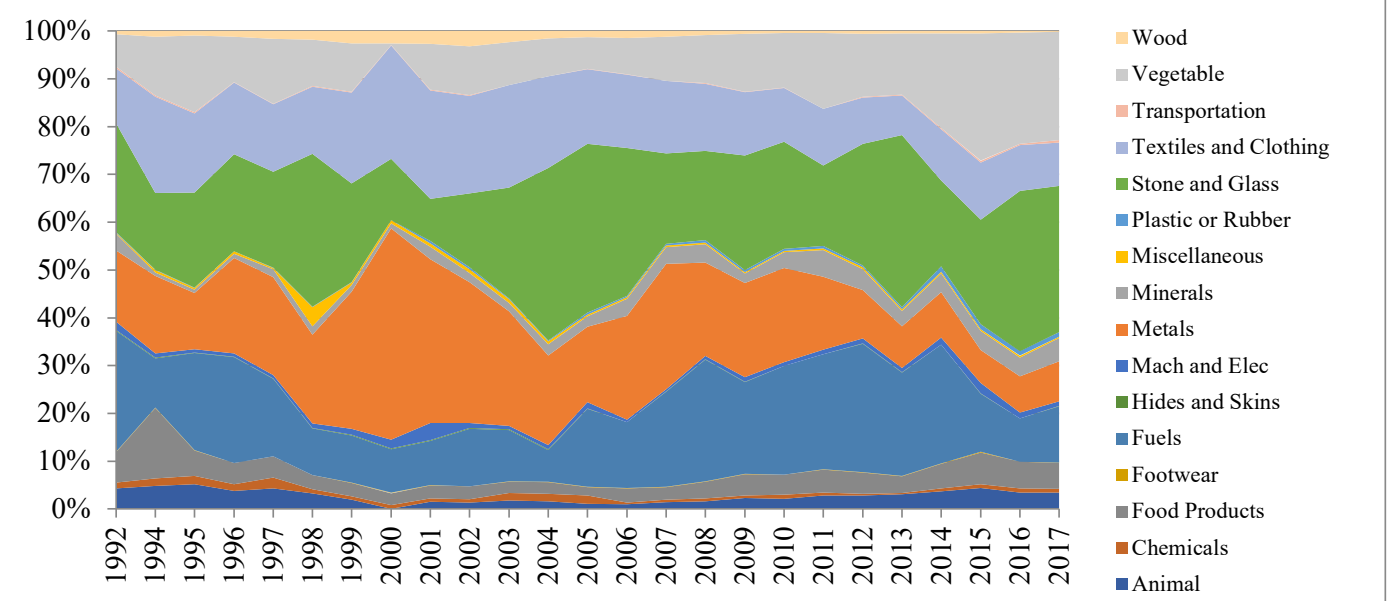

Appendix 5: Share of Peru's Import to the United States by Larger Sector (16 Sectors) 


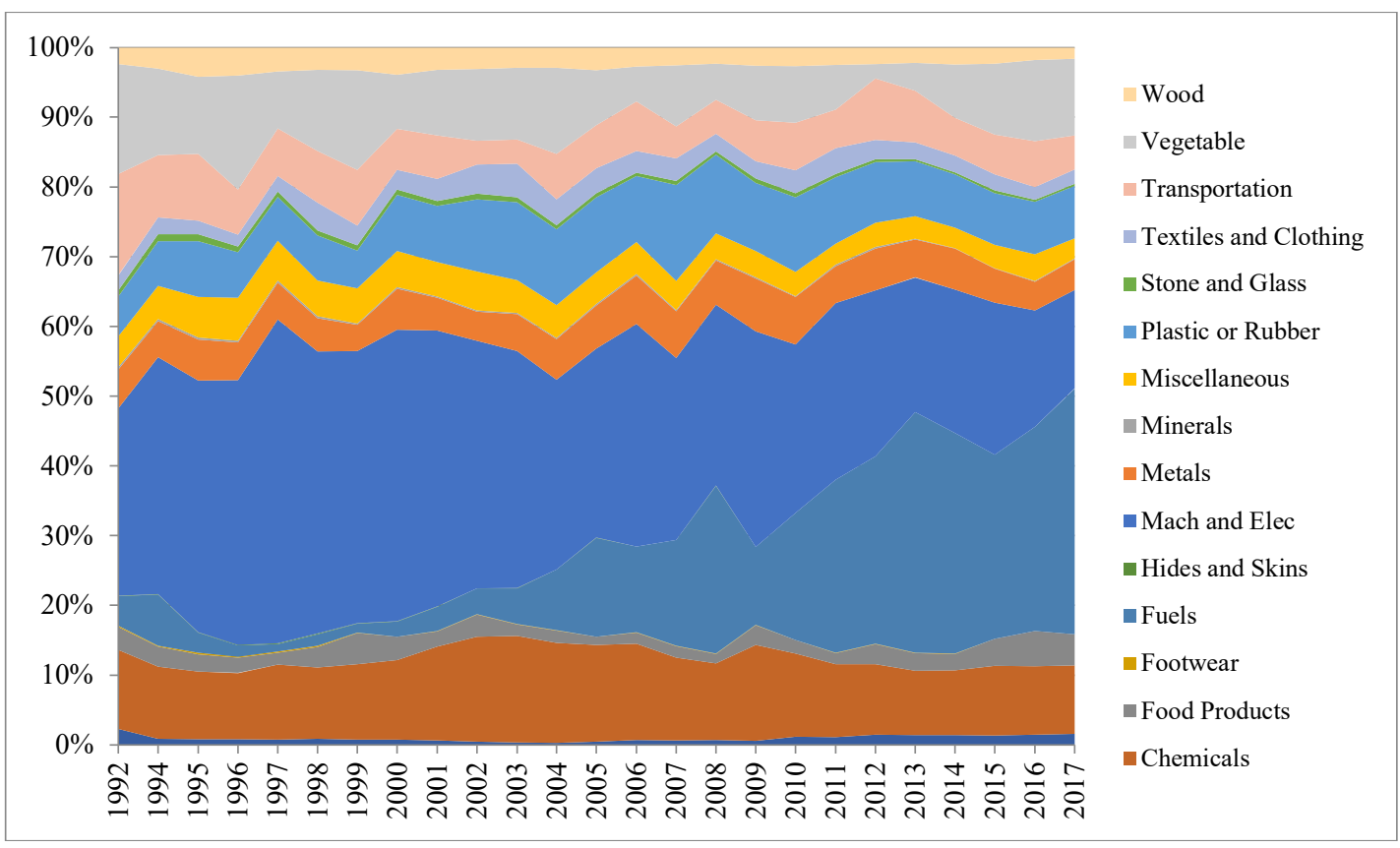

\section{References}

Asia-Pacific Economic Cooperation (APEC). (n.d.). Retrieved from https://ustr.gov/issue-areas/tradeorganizations/asia-pacific-economic-cooperation-apec

Balassa, B. (1965). Trade Liberalization and "Revealed" Comparative Advantage. The Manchester School, 33(2), 99-123.

Balassa, B. (1977). Revealed Comparative Advantage Revisited: An Analysis of Relative Export Shares of the Industrial Countries, 1953-1971. The Manchester School of Economic \& Social Studies, 45(4), 327-344.

Balassa, B. (1979). The changing pattern of comparative advantage in manufactured goods. The Review of Economics and Statistics, 259-266.

Bano, S. (2014). An Empirical Examination of Trade Relations between New Zealand and China in the Context of a Free Trade Agreement.

Bano, S., \& Tabbada, J. (2012). Economic relations between New Zealand and the Philippines: An empirical analysis. Paper presented at the 53rd New Zealand Association of Economists Annual Conference, Palmerston North.

Bela, B. a. (1986). Comparative Advantage in Manufactured Goods: A Reappraisal. The Review of Economics and Statistics, 68(2), 315-319.

Bhattacharyay, B. N., \& Mukhopadhyay, K. (2015). A comprehensive economic partnership between India and Japan: Impact, prospects and challenges. Journal of Asian Economics, 39, 94-107.

Brown, A. J. (1974). Applied economics: Aspects of the world economy in war and peace. London: Allen and Urwin.

Database, U. C. (2016). Database of UN COMTRADE. Retrieved from: https://comtrade.un.org/

De Benedictis, L., \& Tamberi, M. (2001). A note on the Balassa index of revealed comparative advantage. Available at SSRN 289602.

Enrique Fernandez Maldonado. "EL TLC CON ESTADOS UNIDOS Y SU IMPACTO SOBRE EL EMPLEO". En Revista Argumentos, Edición $\mathrm{N}^{\circ}$ 1, Marzo 2009. Disponible en https://revistaargumentos.iep.org.pe/articulos/el-tlc-con-estados-unidos-y-su-impacto-sobre-el-empleo/ ISSN 2076-7722

Fahmi, A. S., Maksum, M., \& Suwondo, E. (2015). USFDA Import Refusal and Export Competitiveness of Indonesian Crab in US Market. Agriculture and Agricultural Science Procedia, 3, 226-230.

FAO. (2015). RCA Indices (pp. 69). Banckok FAO (Food and Agricultural Organization of United Nations).

Fertö, I., \& Hubbard, L. J. ( 2002). Revealed comparative advantage and competitiveness in Hungarian Agri-food sectors. In I. o. E. H. a. o. sciences (Ed.), Discussion papers new series. Budapest, . Budapest, Hungary: Institute of Economics Hungarian academy of sciences.

Hanson, G. H., Lind, N., \& Muendler, M.-A. (2015). The Dynamics of Comparative Advantage: National Bureau of Economic Research. 
Kojima, K. (1964). The pattern of international trade among advanced countries. Hitotsubashi Journal of Economics, 5(1), 16-36.

NAFTA (n.d.). Retrieved May 8, 2019, from http://www.investorwords.com/5670/NAFTA.html

Perú. (n.d.). Retrieved May 8, 2019, from https://www.bancomundial.org/es/country/peru

Peru Trade Promotion Agreement. (n.d.). Retrieved from https://ustr.gov/trade-agreements/free-tradeagreements/peru-tpa

Portal Institucional e Información sobre la Actividad Parlamentaria y Legislativa del Estado Peruano. (n.d.). Retrieved from http://www.congreso.gob.pe/

Raj, P. S., Wing, E., \& Ambrose, D. (2014). A brief analysis of India-Japan bilateral trade: A trade intensity approach. International Journal of Economics, Commerce and Management, Vol. II(2).

Sanidas, E., \& Shin, Y. (2010). Comparison of revealed comparative advantage indices with application to trade tendencies of East Asian countries. Paper presented at the 9th Korea and the World Economy Conference, Incheon.

Seyoum, B. (2007). Revealed comparative advantage and competitiveness in services: A study with special emphasis on developing countries. Journal of Economic Studies, 34(5), 376-388.

UNSCAP, A. (2016). Trade Intensity $\quad-\quad$ Technical Notes. Retrieved from: http://artnet.unescap.org/APTIAD/trade\%20intensity.pdf

WITS. (2013). Trade Outcomes Indicators. Retrieved from: http://wits.worldbank.org/WITS/docs/TradeOutcomes-UserManual.pdf

WTO. (2016). WTO Time Series Data (Accessed in December 2016). from http://stat.wto.org/Home/WSDBHome.aspx

Youssef, O. (2016, May 09). Why The United States Economy Will Remain The Strongest In The World. Retrieved from https://www.worldatlas.com/articles/10-reasons-the-united-states-economy-couldremain-the-strongest-in-the-world.html 